\title{
Cost effectiveness in River Management: Evaluation of Integrated River Policy System in Tidal Ouse
}

\author{
Tao Wang*
}

\begin{abstract}
The River Ouse forms a significant part of Humber river system, which drains about one fifth land area of the England and provides the largest fresh water source to the North Sea from UK. The river quality in the tidal river suffered from sag of dissolved oxygen (DO) during last few decades, deteriorated by the effluent discharges. The Environment Agency (EA) proposed to increase the water quality of Ouse by implementing more potent environmental policies. This paper explores the cost effectiveness of water management in the Tidal Ouse through various options by taking into account the variation of assimilative capacity of river water, both in static and dynamic scope of time. Reduction in both effluent discharges and water abstraction were considered along side with choice of effluent discharge location. Different instruments of environmental policy, the emission tax-subsidy (ETS) scheme and tradable pollution permits (TPP) systems were compared with the direct quantitative control approach. This paper at the last illustrated an empirical example to reach a particular water quality target in the tidal Ouse at the least cost, through a solution of constrained optimisation problem. The results suggested significant improvement in the water quality with less cost than current that will fail the target in low flow year.
\end{abstract}

Key words: water quality management, tradable pollution permits, tax and subsidy, effluent discharge, water abstraction, dynamic equilibrium, integrated river policy, cost effectiveness

\section{$\underline{\text { 1. Introduction }}$}

\subsection{Problem in the tidal Ouse}

The river Ouse forms part of the Humber river system, which drains about one fifth of the land area of England. The Humber estuary, which is the largest fresh water source to the North Sea from UK, together with its tributaries and other eastern rivers contain a

\footnotetext{
* Environment Department, University of York, Heslington, York YO10 5DD, UK
} 
richer fish fauna than any other rivers in England. A big proportion of the Humber catchment is densely populated and industrialised, most of which is drained by Yorkshire Ouse and Trent systems. The confluences of the main tributaries of Ouse are downstream of its tidal limit, with only a quarter of the flow from the non-tidal catchment (Edwards et al. 1997). The Humber river system is shown in Figure 1 as below. This paper focuses on the water quality in the tidal Ouse along with its tributaries Wharfe, Derwent, Aire and Don.

Salmon were common in the Ouse up to the nineteenth century. However, development of industries along the various tributaries in the late eighteenth and early nineteenth centuries led to an enormous increase in effluent discharged to the river. This together with some other factors led to the reduction of salmon in the Ouse. As a result, the EA chose salmon as a key indicator of the river's ecological health, and proposed to improve water quality by implementing more effective environmental policies (Cashman et al. 1999). This Paper aims to evaluate the cost effectiveness of water management and pollution control in the tidal Ouse through different options, taking into account both effluent discharges and water abstraction.

\subsection{Water quality management in the Tidal Ouse}

Although the river quality has been improved significantly in Ouse system in the last ten years, it still suffers from the DO sag in the summer months, especially downstream of Selby industrial effluent discharges. As a result DO levels in some parts of the river and at some times of the year are too low to support fish. The worst DO sag locates around Selby and Long Drax during the summer months, preventing the returned salmon. The decline of salmon stock in the Ouse system is due to a number of factors, which includes over-fishing around Greenland, commercial netting in estuaries, habitat loss, increased sediment load and river morphology changes. But effluent discharges from the industries were regarded as the primary cause of DO sag. Rainfall also varies dramatically over space and time in the catchment region, with highest rainfall over $1600 \mathrm{~mm}$ p.a. in parts of Pennines and in the winter due to the prevailing wind (Law et al. 1997), and much less rainfall in Southeast catchment and dry summer. The inland penetration of tides during low flows transports sediment upstream, while resuspension of sediments results in considerable DO consumption. In addition, large quantities of river water are abstracted and transferred through its grid by Yorkshire Water to supply portable water for over 3.5 million people, and returned to the river system through sewage treatment works. One obvious effect on the water quality in the tidal Ouse is the 
reduction of clean freshwater flows from northern rivers and rising volume of poor quality water returned from the industrial south tributaries (Edwards et al. 1997)

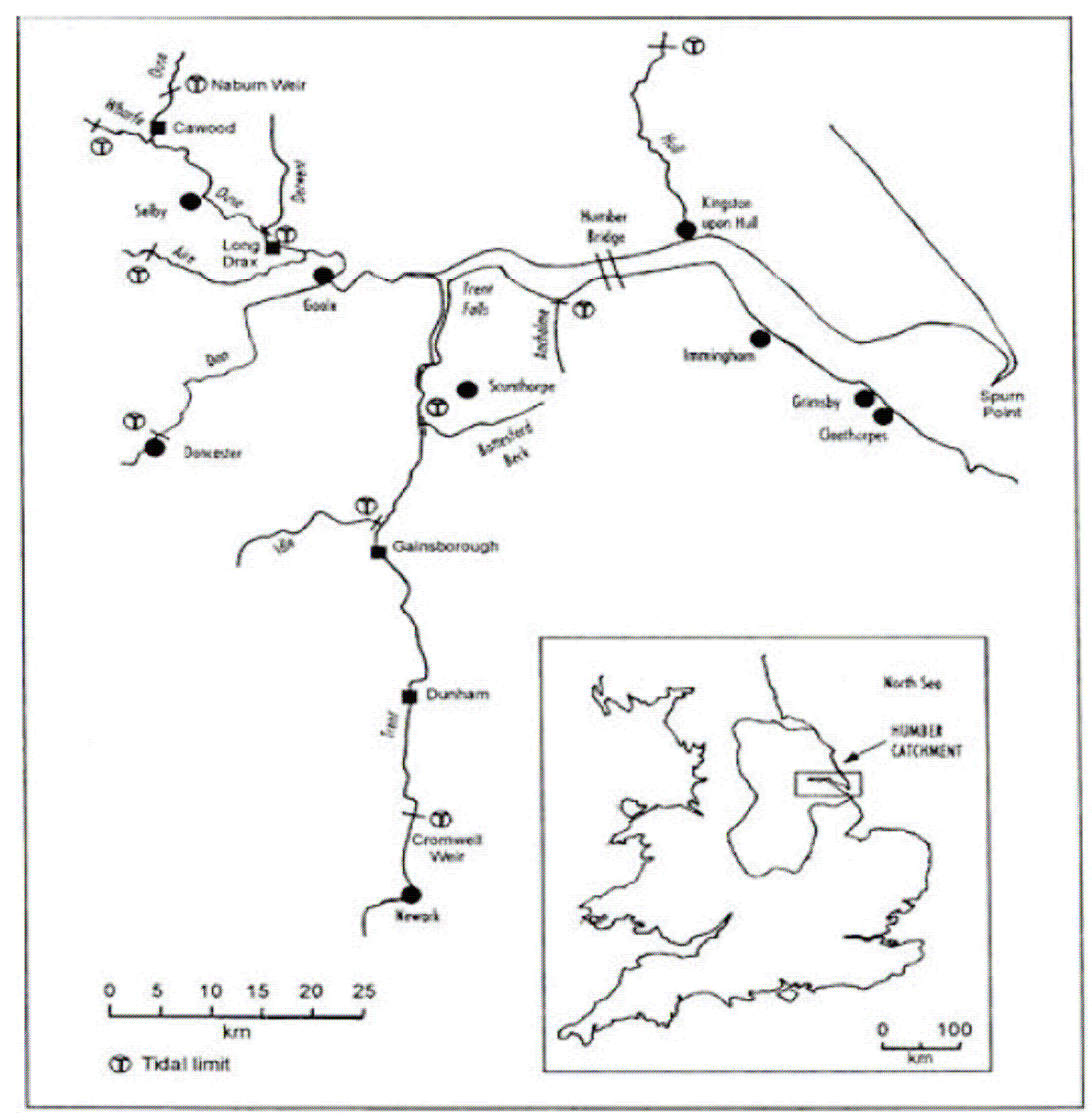

Figure 1. The tidal section of Hum ber. Trent and Ouse system and m a m tributaries Source: Tavom et a1. 2003 iredram from National Rirers Authority/ 1993 II

The EA intends to improve river water quality by tightening discharge consents in Selby. A new system of pollution control is being implemented in order to restore water quality in the Ouse, which is driven by the EU Directive on Integrated Pollution Prevention and Control (IPPC). The essence of IPPC is that operators should choose the best option available to achieve an agreed level of protection of the environment taken as a whole. The Best Available Techniques (BAT) approach is typically modified by the declaration that the cost of applying techniques should not be excessive in relation to the environmental protection it provides. However, the IPPC Scheme requires BAT to be applied in the abatement of pollution while no clear definition of BAT is provided. A 
more rigorous way of addressing the issue of cost is to identify the most cost effective method for achieving a given targeted reduction on emissions.

Water abstraction has impacts on river water quality as well as effluent discharges. Since river volume affects the assimilative capacity, it is apparent that water abstraction has adverse impacts on river water quality, and the effects are interdependent of the effects of effluent discharged into the river body. Therefore, it is necessary to include both industrial effluent and water abstraction in an integrated regulation system. To date, however, effluent discharge consents and water abstraction licenses have not taken into account variation in the assimilative capacity of river, or the interdependence of effluent and water abstraction.

The current regulatory system controlling effluent discharge and water abstraction in Tidal Ouse and Humber estuaries is characterized by two different policies both implemented by the EA: discharge consents for effluents and a system of tradable Water Abstraction Licenses for water abstractions respectively. The consents for effluents take fixed value over the year, though some allow certain extent of variation and violation over the year. An abstraction licence generally states how much water may be taken, from where it may be taken, how it may be used and where it may be returned to river. Water abstraction licenses recently became time limited and can only be renewed upon application. However, the amount granted each license is given on the annual basis and allows the abstractor to take water from river any time of the year, no matter what the river condition is.

Because of these inefficiencies in the current regulations system, excessive social costs are carried by both the industries involved and the local economy that they serve. Most firms that discharge effluents into the tidal Ouse are located in the Selby area. The extra costs imposed by regulations may have significant impacts on the local economy and residents. This paper explored the potential cost advantages of rive policy based on the variation of assimilative capacity or river water. Using a water quality model developed for the EA to set the effluent consents, this research evaluated the potential options in water quality management that are available for the tidal Ouse following the variation of assimilative capacity. This paper also derived a simplified system of water quality functions through regression for the tidal Ouse, based on the most influencing factors to the $\mathrm{DO}$ saturation ( $\mathrm{DO} \%$ ) of river water. This system of water quality function was then combined with the cost functions derived for various water quality management options to construct the static optimisation analysis, which revealed a cost minimisation solution for a given water quality compliance required by the EA. The cost minimisation solution was able to significantly improve the water quality and remove 
the DO sag even for one of the years with the least river flow and the worst ambient water quality, while still having a cost saving of $£ 200,000$ per year to the current annual costs of water management in the tidal Ouse. This integrated river policy considered in this optimisation does not just imply integration on effluent discharges and water abstractions, but also the physical effect on water quality and the social cost of water management, which is consistent to the requirement of the most recent European regulation of Water Framework Directive (WFD).

\subsection{The structure of the paper}

The paper consists of six sections. The second section discussed two previous researches for the pollution control in the estuarine systems in UK that initiate the evaluation of cost for water quality improvement. These were compared with this research as well.

A third section offers a static analysis of environment policy to control pollution along the river when the spatial location of effluent sources and water abstraction were referred in the river regulation. This paper discussed the necessary condition to achieve the least cost for a particular water quality target under a static system and the underlined economic interpretation.

The fourth section offered dynamic analysis for the same issue, when the relevant activities to control water quality were driven by the investment and capital stock within the sector. The cost minimisation under the dynamic system led to an unstable equilibrium of saddle point, in which the steady state can only be reached through specific investment path. I also discussed differences between the equilibria of the ETS scheme and the TPP system, which are usually the same under static analysis. Comparative statics indicate the direction of change in the dynamic system caused by the policy instruments, when alteration is necessary to achieve the prescribed environmental target.

Section five illustrated an empirical example of water quality improvement in the tidal Ouse, through an integrated measure consistent to the variation of assimilative capacity of river water, to achieve the given water quality target at the least costs. The section discussed the methods and solution of the constrained optimisation problem, showing that the water quality could be dramatically improved following the solution generated with more than $£ 200,000$ cost saving over the current cost of water quality management which cannot prevent the DO sag in low flow conditions.

\section{Pollution Control in Estuarine System}


Although most economists agree that Market Based Instruments (MBIs) are more efficient both in cost saving and dynamic incentives over Command and Control (CAC) approaches (Oates and Strassmann 1984; Baumol and Oates 1988; Perman et al. 1996; Hanley et al. 1997; Cowan 1998), uncertainty over both pollution-related environmental damage and costs and benefits estimates, the significance of hazardous environmental risks, and significance of fixed costs could reduce their advantages over the direct regulatory standards (Turner et al. 1994; Zylicz 2003). Since estuarine system involves considerable uncertainty, it is a moot point to say MBIs are necessarily more appropriate. Two papers have discussed the implications of market-based instruments for UK estuaries.

\section{(a) The Tees Estuary Study (Rowley 1979)}

In 1979, the Tees Estuary was so "grossly polluted" that it was not able to support fisheries from Stockton to the mouth of the estuary. Research by Rowley et al. investigated the possibility of utilizing an emission charge rather than regulatory consents to control pollution in the estuary and to achieve satisfactory water quality. Nine major industrial pollution sources were included in an economic model in which a least-cost solution was found, using transfer coefficients from a water quality model. Appropriate charge rates were identified for particular water quality targets. The study found that the cost of reaching the desired water quality objective would be much lower using emission charge instruments than regulatory consents. It also found that control costs were sensitive to the time period within which the target was required to be met. Hence emission charge rates were different in different stretches. However, information asymmetry between the regulator and industrial sources, and the stepwise nature of the marginal cost function complicated implementation. The monitoring and enforcement of the emission charge was also projected to be expensive to administer. Overall, the study questioned the feasibility of the emission charge instrument.

(b) The Forth Estuary in Scotland (Hanley and Moffatt 1993; Hanley et al. 1998)

The Forth Estuary located in central Scotland is a multi-use resource, providing water supply for industrial use, recreation, habitat and effluent disposal from industrial and sewage works. The most significant problem was seasonal DO sag as in the Ouse, associated with low flow and high temperature conditions. As a result some stretches of the river fail to comply with Environmental Quality Standards (EQS). The most significant economic effect was thought to be the effects on the salmon fisheries because the low DO\% prevents the return migration of salmon. The direct cause of the DO sag is 
the effluent emission from the sewage works and industrial processes, among which industrial sources accounted for $87 \%$ of total BOD loading.

An economic model was developed to minimize the control costs subject to the environmental constraints, alongside a model of water quality. The author explored the possibility of using a potential tradable permits system to improve the water quality at a lower cost than uniform restriction on each pollution source. Control costs in each plant were evaluated for several BOD load reduction scenarios. The corresponding marginal cost $(\mathrm{MC})$ of control was found to be sensitive to the timescale allowed for the reduction. The potential cost saving was calculated, and compared with the costs of uniform constraints.

In the 1993 paper, Hanley and Moffatt conducted a simulation within which the least cost solution was compared to Tradable Emission Permit (TEP), emission charges and flexible regulations. A novel result showed that the flexible regulation was closest to the least cost solution although it could not provide a continuing incentive to reduce emissions in the most efficient manner. In the 1998 paper, Hanley conducted the analysis under both an Emission Permits System (EPS) and an Ambient Permits System (APS). In EPS, emission permits are traded on a one-to-one base along the whole length of the Estuary. The cost of achieving the target under EPS was increasing at the margin, and large cost savings were proved over the uniform emissions control. In APS the permits are traded on the basis of their transfer coefficients and the target is an improvement in the mean $\mathrm{DO} \%$ in the estuary rather than a cut in BOD loading. The author found a large influence from resuspended bottom sediment on the DO distribution along of the estuary, both from current and past anthropogenic activities.

In both studies, the effect of policy instruments on the pollution control were subjected to static analysis, and only focused on the effluent emissions to the river. This paper integrated water abstraction and effluent discharges, as these are interdependent to their impact on water quality. In addition, the research discussed above did not consider the dynamic problem, but assumed that plants maintained outputs, and the same level of emissions. Both static and dynamic analysis were provided the in this research on the river policy and its cost effectiveness, though the empirical example of tidal Ouse was evaluated against the static analysis alone due to the constraint of data.

\section{$\underline{\text { 3. Static Analysis of Environmental Policy }}$}

The water policies currently implemented in England and Wales dealing with effluent discharge consents and water abstractions are effluent discharge consents and tradable water abstraction licenses. Currently, neither instrument takes account the river 
flow. Since river flow has an impact on assimilative capacity and consequently on river water quality, it is necessary to consider the effect of time-varying and location-specific consents and licenses to cope with variations in river conditions.

\subsection{A General model of cost efficiency of pollution abatement}

I assumed a particular pollution externality produced by several firms in a market. The firms are competitive with each other, and produce a homogenous output $q_{i}$, and during production generate emissions $e_{i}$ to the whole market. With an exogenously determined output price and some inputs invested in pollution abatement, the firm's profit may be defined as follows:

$$
\begin{aligned}
& B\left(q_{i}, \alpha_{i}\right)=p q_{i}-C_{i}\left(q_{i}, \alpha_{i}\right)-\mathrm{T}\left(e_{i}\right) \\
& e_{i}=s_{i}\left(q_{i}, \alpha_{i}\right)
\end{aligned}
$$

$q_{i}$ is product output from site $i$, facing an exogenous price $p ; \alpha_{i}$ denotes the level of abatement activity and $\mathrm{T}\left(e_{i}\right)$ reflects private emission-related costs at site $i$, which can be attributed to the existence of environmental policy (Xepapadeas 1997).

Although regulation of effluent discharges regulated the pollution discharged into the receiving water body, only ambient water quality matters. For the tidal Ouse estuary, there are five Water Quality Monitoring (WQM) sites downstream from Naburn Weir to Blacktoft before its confluence with Tidal Trent at Trent Fall. Water quality in the tidal Ouse is influenced by several factors including the tributaries water qualities, industrial emissions, and water abstractions by water companies as well as volume, velocity and micro plankton activity of the river.

Water quality at site $\mathrm{s}$ is assumed to take the form $Q_{s}=f_{s}\left(A_{s}, E_{s}, H_{s}, \varepsilon_{s}\right)+\gamma_{s}$ and the ambient water quality target at site $s$ is $\bar{Q}_{s}$. It follows that the water quality at WQP s must satisfy $Q_{s} \geq \bar{Q}_{s}, \forall s$, where

$A_{s}$ is background water quality including the inputs from other tributaries at WQP site s, $E_{s}$ is aggregate industrial effluent discharge at WQP site s, $H_{s}$ is aggregate water abstraction at WQP site $\mathrm{s}$,

$\varepsilon_{s}$ is a vector of other environmental factors that will influence the water quality, including velocity, volume, river flow and tide etc, and 
$\gamma_{s}$ is variations not captured by this function.

When locations of effluent discharge and water abstraction matter, a simple sum of emissions and abstraction from all the sources are not appropriate. Instead, transfer coefficients of impacts on the water quality at various water quality sites from different sources are applied to evaluate the aggregate impacts. It is assumed that the sources linearly contribute to the aggregate emissions or abstractions on the water quality at WQP site $s$. Thus

$$
\begin{aligned}
& E_{s}=b_{1 s} e_{1}+b_{2 s} e_{2}+\cdots \cdots+b_{k s} e_{k}=\sum_{i=1}^{k} e_{i s}=\sum_{i=1}^{k} b_{i s} e_{i}, \\
& H_{s}=d_{1 s} \beta_{1}+d_{2 s} \beta_{2}+\cdots \cdots+d_{k s} \beta_{k}=\sum_{i=1}^{k} \beta_{i s}=\sum_{i=1}^{k} d_{i s} \beta_{i},
\end{aligned}
$$

where $b_{i s}$ and $d_{i s}$ are the transfer coefficients of impact from the pollution discharge or water abstraction at site $i$ on the water quality at site $s . e_{i}$ and $\beta_{i}$ are the effluent discharge and water abstraction at site $i$ respectively.

\subsection{Static Cost effectiveness in ambient water quality control}

Let the cost function of each plant at site $i$, either industrial plant or water company, take the form of $C_{i}\left(q_{i}, a_{i}, \beta_{i}\right)$ where $q_{i}$ and $a_{i}$ are the industrial output and abatement level at site $i$ respectively, and $\beta_{i}$ is the amount of water abstraction at site $i$. Assume that for any combination of $q_{i}$ and $a_{i}$, the industrial effluent discharge to the river from site $i, e_{i}$, can be determined. At this point in time, no firm both discharges effluent to river and abstracts water at the same time in Selby. Many sources of emissions to the Ouse currently use ground water for their production process. Nevertheless, I allow for the case where a firm at site $i$ has $e_{i}>0$ and $\beta_{i}>0$ at the same time. For a pure effluent discharger, $\beta_{i}=0$ and vice versa. Therefore the cost effective allocation of effluent abatement and water abstraction is the solution to the following problem:

Minimize $\sum_{i} C_{i}\left(q_{i}, a_{i}, \beta_{i}\right)$

Subject to: $Q_{s}=f_{s}\left(A_{s}, E_{s}, H_{s}, \mathcal{E}_{s}\right)+\gamma_{s} \geq \bar{Q}_{s}$, for all the $s=1,2 \ldots r$.

The Lagrange Equation is: 
$L=\sum_{i} C_{i}\left(q_{i}, a_{i}, \beta_{i}\right)+\sum_{s} \lambda_{s} \cdot\left(\bar{Q}_{s}-f_{s}\left(A_{s}, E_{s}, H_{s}, \varepsilon_{s}\right)-\gamma_{s}\right)$. Under the assumption of convexity of the cost functions, the Kuhn-Tucker conditions to this optimisation problem include:

$\frac{\partial C_{i}(\cdot)}{\partial q_{i}}-\sum_{s} \lambda_{s} b_{i s} \frac{\partial f_{s}(\cdot)}{\partial E_{s}} \cdot \frac{\partial e_{i}}{\partial q_{i}} \geq 0 ;$

$\left[\frac{\partial C_{i}(\cdot)}{\partial q_{i}}-\sum_{s} \lambda_{s} b_{i s} \frac{\partial f_{s}(\cdot)}{\partial E_{s}} \cdot \frac{\partial e_{i}}{\partial q_{i}}\right] \cdot q_{i}=0, \forall i$

$\frac{\partial C_{i}(\cdot)}{\partial a_{i}}-\sum_{s} \lambda_{s} b_{i s} \frac{\partial f_{s}(\cdot)}{\partial E_{s}} \cdot \frac{\partial e_{i}}{\partial a_{i}} \geq 0$

$\left[\frac{\partial C_{i}(\cdot)}{\partial a_{i}}-\sum_{s} \lambda_{s} b_{i s} \frac{\partial f_{s}(\cdot)}{\partial E_{s}} \cdot \frac{\partial e_{i}}{\partial a_{i}}\right] \cdot a_{i}=0, \forall i$

$\frac{\partial C_{i}(\cdot)}{\partial \beta_{i}}-\sum_{s} \lambda_{s} d_{i s} \frac{\partial f_{s}(\cdot)}{\partial H_{s}} \geq 0$

$\left[\frac{\partial C_{i}(\cdot)}{\partial \beta_{i}}-\sum_{s} \lambda_{s} d_{i s} \frac{\partial f_{s}(\cdot)}{\partial H_{s}}\right] \cdot \beta_{i}=0, \forall i$

$\bar{Q}_{s}-f_{s}\left(A_{s}, E_{s}, H_{s}, \varepsilon_{s}\right)-\gamma_{s} \leq 0 ;$

$\left(\bar{Q}_{s}-f_{s}\left(A_{s}, E_{s}, H_{s}, \varepsilon_{s}\right)-\gamma_{s}\right) \cdot \lambda_{s}=0, \forall s$

$q_{i}, a_{i}, \beta_{i}, \lambda_{s} \geq 0, \forall i, \forall s$

$q_{i}, a_{i}, \beta_{i}, \lambda_{s}$ are all assumed to be positive unless there is plant shut down or any WQP is of no interest of protection. Therefore it follows:

$$
\begin{aligned}
& \frac{\partial C_{i}(\cdot)}{\partial q_{i}^{*}}=\sum_{s} \lambda_{s} b_{i s} \frac{\partial f_{s}(\cdot)}{\partial E_{s}} \cdot \frac{\partial e_{i}}{\partial q_{i}^{*}} \\
& \frac{\partial C_{i}(\cdot)}{\partial a_{i}^{*}}=\sum_{s} \lambda_{s} b_{i s} \frac{\partial f_{s}(\cdot)}{\partial E_{s}} \cdot \frac{\partial e_{i}}{\partial a_{i}^{*}} \\
& \frac{\partial C_{i}(\cdot)}{\partial \beta_{i}^{*}}=\sum_{s} \lambda_{s} d_{i s} \frac{\partial f_{s}(\cdot)}{\partial H_{s}} \\
& f_{s}\left(A_{s}, E_{s}, H_{s}, \varepsilon_{s}\right)+\gamma_{s}=\bar{Q}_{s}
\end{aligned}
$$


Taking the effects on the catchment as a whole, cost effectiveness implies that $\lambda_{i}=\lambda_{j}=\cdots=\lambda_{s}=\lambda$ for all the WQP sites if they are all binding, which implies that

$$
\frac{\partial C_{i}(\cdot) / \partial q_{i}^{*}}{\sum_{s} b_{i s} \frac{\partial f_{s}(\cdot)}{\partial E_{s}} \cdot \frac{\partial e_{i}}{\partial q_{i}^{*}}}=\frac{\partial C_{i}(\cdot) / \partial a_{i}^{*}}{\sum_{s} b_{i s} \frac{\partial f_{s}(\cdot)}{\partial E_{s}} \cdot \frac{\partial e_{i}}{\partial a_{i}^{*}}}=\frac{\partial C_{i}(\cdot) / \partial \beta_{i}^{*}}{\sum_{s} d_{i s} \frac{\partial f_{s}(\cdot)}{\partial H_{s}}}=\lambda
$$

Equation (3.17) has clear economic meaning. The cost effective allocation of effluent abatement and water abstraction in the catchment requires the output, abatement and abstraction from site $i$ have the same ratio between marginal private cost and marginal impact on the river water quality at all the WQP sites. To be cost efficient, this would equal to the marginal social value of ambient water quality improvement at each site. To be cost effective, the environmental target is met at least cost to society. By switching the target from cost efficiency to cost effectiveness, the exact value of shadow price is no longer a constraint for the allocation of emissions and abstraction. Actually, for whatever the ratio is, cost effectiveness will be achieved as long as the prescribed environment quality targets are not violated, i.e.

$$
\frac{\partial C_{i}(\cdot) / \partial q_{i}^{*}}{\sum_{s} b_{i s} \frac{\partial f_{s}(\cdot)}{\partial E_{s}} \cdot \frac{\partial e_{i}}{\partial q_{i}^{*}}}=\frac{\partial C_{i}(\cdot) / \partial a_{i}^{*}}{\sum_{s} b_{i s} \frac{\partial f_{s}(\cdot)}{\partial E_{s}} \cdot \frac{\partial e_{i}}{\partial a_{i}^{*}}}=\frac{\partial C_{i}(\cdot) / \partial \beta_{i}^{*}}{\sum_{s} d_{i s} \frac{\partial f_{s}(\cdot)}{\partial H_{s}}}=a
$$

where $a$ reflects the preference of choice of the environmental authority.

\section{Dynamic Analysis of Environmental Policy}

\subsection{Dynamic problem with continuous time}

In the dynamic system, output, abatement and abstraction are dynamic functions of the capital stock available to the firm (assuming that the costs of labour are negligible compared with capital costs, and could be included in the operational costs). The initial capital stock of firm depends on prior investment, which is exogenous in the model, and depreciation of the capital stock. The output, abatement and abstraction are assumed as below to be functions of their capital stocks, which are dynamic against time.

$$
\begin{aligned}
& q_{i}(t)=q_{i}\left(k_{i}^{q}(t)\right) \\
& a_{i}(t)=a_{i}\left(k_{i}^{a}(t)\right) \\
& \beta_{i}(t)=\beta_{i}\left(k_{i}^{\beta}(t)\right)
\end{aligned}
$$


The problem then is to identify the optimal future investment path under different environmental policy instruments, and to evaluate their feasibility. The time horizon of the dynamic problem is taken to be infinity. This is not necessarily because that the firm or environment authority has a prospect of sustainable development for infinite time, but even if the time horizon of planning were finite, the remaining value still have to be estimated at the horizon by discounting what they are in the future (Aronsson et al. 2004). Therefore, the optimisation problem may be written as, $\underset{F(t)}{\operatorname{Max}} \sum_{t=0}^{T} \rho^{t} \cdot F(t)+V(T)=\sum_{t=0}^{T} \rho^{t} \cdot F(t)+\sum_{t=T}^{\infty} \rho^{t} \cdot F(t)=\sum_{t=0}^{\infty} \rho^{t} \cdot F(t)$. That is, the optimisation problem in a finite horizon will end up the same as the problem in an infinite horizon. In this paper, the firm's objective is to minimize the aggregate costs of achieving the desired water quality level. The environment authority is to maintain water quality at least at the required level during whatever the policy horizon.

The objective is to achieve the environmental target at minimum cost:

$$
\begin{aligned}
& \underset{I_{i}^{j}}{\operatorname{Min}} \int_{0}^{\infty} e^{-r t} \cdot \sum_{i} C_{i}\left(q_{i}, a_{i}, \beta_{i}, I_{i}^{j}\right) \\
& \text { s.t. } \dot{k}_{i}^{j}=I_{i}^{j}(t)-\delta_{i}^{j} k_{i}^{j}(t), j=q, a, \beta, \\
& \qquad Q_{s}=f_{s}\left(A_{s}, E_{s}(t), H_{s}(t), \varepsilon_{s}\right)+\gamma_{s} \geq \bar{Q}_{s},
\end{aligned}
$$

$k_{i}^{j}(0)$ is given.

The current value Hamiltonian of this dynamic problem is

$$
\hat{H}=\sum_{i}\left[C_{i}\left(q_{i}(t), a_{i}(t), \beta_{i}(t), I_{i}^{j}(t)\right)+\sum_{j} \mu_{i}^{j}(t) \cdot\left(I_{i}^{j}(t)-\delta_{i}^{j} \cdot k_{i}^{j}(t)\right)\right]
$$

The corresponding Lagrange Equation is

$$
L=\hat{H}+\sum_{s} \lambda_{s}(t) \cdot\left(\bar{Q}_{s}-f_{s}\left(A_{s}, E_{s}(t), H_{s}(t), \varepsilon_{s}\right)-\gamma_{s}\right)
$$

The FOCs are

$$
\begin{aligned}
& I_{i}^{j} \cdot\left(\frac{\partial C_{i}^{*}(\cdot)}{\partial I_{i}^{j}}+\mu_{i}^{j}\right)=0, I_{i}^{j} \geq 0 \\
& \lambda_{s} \cdot\left[\bar{Q}_{s}-f_{s}^{*}\left(A_{s}, E_{s}(t), H_{s}(t), \varepsilon_{s}\right)-\gamma_{s}\right\rfloor=0, \lambda_{s} \geq 0
\end{aligned}
$$


$r \mu_{i}^{j}-\dot{\mu}_{i}^{j}=\frac{\partial L^{*}}{\partial k_{i}^{j}} \Rightarrow \dot{\mu}_{i}^{j}=\left(r+\delta_{i}^{j}\right) \mu_{i}^{j}-\frac{\partial C_{i}^{*}(\cdot)}{\partial k_{i}^{j}}+\sum_{s} \lambda_{s} \cdot \frac{\partial f_{s}^{*}(\cdot)}{\partial k_{i}^{j}}$

$\frac{\partial L^{*}}{\partial \mu_{i}^{j}}=0 \Rightarrow \dot{k}_{i}^{j}=I_{i}^{j *}-\delta_{i}^{j} k_{i}^{j *}$

and the transversality condition is

$\lim _{t \rightarrow \infty} e^{-r t} \cdot \mu_{i}^{j}(t) \cdot k_{i}^{j}(t)=0$

From (4.6)

$\mu_{i}^{j *}=-\frac{\partial C_{i}^{*}(\cdot)}{\partial I_{i}^{j}}=-C_{i}^{\prime}\left(I_{i}^{j *}\right)$

$\frac{\partial I_{i}^{j}}{\partial \mu_{i}^{j}}=\frac{1}{\partial \mu_{i}^{j} / \partial I_{i}^{j}}=-C_{i}^{\prime \prime}\left(I_{i}^{j *}\right)^{-1}, \forall j$

Therefore,

$\dot{\mu}_{i}^{j}=\frac{\partial \mu_{i}^{j}}{\partial t}=-\frac{\partial C_{i}^{\prime}\left(I_{i}^{j *}\right)}{\partial t}=-\frac{\partial C_{i}^{\prime}\left(I_{i}^{j *}\right)}{\partial I_{i}^{j}} \cdot \frac{\partial I_{i}^{j}}{\partial t}=-C_{i}^{\prime \prime}\left(I_{i}^{j *}\right) \cdot \dot{I}_{i}^{j}$

then substitute Eq. (4.13) into Eq. (4.8),

$\dot{I}_{i}^{j}=-\frac{1}{C_{i}^{\prime \prime}\left(I_{i}^{j *}\right)} \cdot\left[\left(r+\delta_{i}^{j}\right) \mu_{i}^{j *}-\frac{\partial C_{i}^{*}(\cdot)}{\partial k_{i}^{j}}+\sum_{s} \lambda_{s} \cdot \frac{\partial f_{s}^{*}(\cdot)}{\partial k_{i}^{j}}\right]$

Eq. (4.14) and Eq. (4.9) could form a Hamiltonian dynamic system regarding the dynamic control variable of investment $I_{i}^{j}$, and the state variable, capital stocks $k_{i}^{j}$.

The steady state is defined at the point $\left(I_{i}^{j *}, k_{i}^{j *}\right)$, when $\dot{I}_{i}^{j}=\dot{k}_{i}^{j}=0, \forall i, \forall j$.

Then from Eq. (4.9) and (4.14),

$I_{i}^{j *}=\delta_{i}^{j} \cdot k_{i}^{j *}$

$\frac{1}{\mu_{i}^{j *}} \cdot\left(\frac{\partial C_{i}^{*}(\cdot)}{\partial k_{i}^{j}}-\sum_{s} \lambda_{s} \cdot \frac{\partial f_{s}^{*}(\cdot)}{\partial k_{i}^{j}}\right)-\delta_{i}^{j}=r$

Eq. (4.15) and (4.16) have clear economic interpretations. Eq. (4.15) says that in the long-run steady state, investment in all the three activities should equal the depreciation rate of capital in these activities so that the capital stocks remain at a constant level. This equation implies some economic interpretation. The right hand side of Eq. (4.16) is the interest rate and discount factor or average rate of return in capital in the economy. The 
left hand side consists of two parts. The first part, similar as in the static analysis, is the marginal effects of an extra unit of capital committed to output, abatement, or abstraction on the firm's individual costs, net of the marginal shadow value of capital committed to environmental quality. The second part is the depreciation rate of the capital stock. The right hand side is then the overall average rate of return of the capital invested in the plant. Therefore, in the steady state equilibrium, investment should increase up to the point where it yields the same rate of return as in other area of the economy. Overall Eq.(4.16) states that under the optimal investment management, the internal rate of return of the capital stock should equal the rate of return of capital invested in elsewhere in economy.

\subsection{The Stability Property of Equilibrium}

The steady state may be found by setting the motion of costate, state and control variables of the dynamic system to zero, which in our case are the variables of $\mu_{i}^{j}, k_{i}^{j}$ and $I_{i}^{j}$. However, knowing the steady state equilibrium is not very meaningful without knowing stability of the dynamic system. An equilibrium point that only exists in principle, but cannot be reached, and which is such that the slightest disturbance leads to divergence - an unstable equilibrium point - is obliviously not very relevant from an economic point of view (Gandolfo 1997). The following analysis investigated the stability properties of the dynamic system.

\subsubsection{Dynamic system of $\dot{k}_{i}^{j}, \dot{I}_{i}^{j}$}

I already have that

$$
\begin{aligned}
& \dot{I}_{i}^{j}=-\frac{1}{C_{i}^{\prime \prime}\left(I_{i}^{j *}\right)} \cdot\left[\left(r+\delta_{i}^{j}\right) \mu_{i}^{j}-\frac{\partial C_{i}^{*}(\cdot)}{\partial k_{i}^{j}}+\sum_{s} \lambda_{s} \cdot \frac{\partial f_{s}^{*}(\cdot)}{\partial k_{i}^{j}}\right] \\
& \dot{k}_{i}^{j}=I_{i}^{j *}-\delta_{i}^{j} k_{i}^{j *}=F\left(k_{i}^{j}, I_{i}^{j}\right)
\end{aligned}
$$

From Eq. (4.11), $\mu_{i}^{j *}=-C_{i}^{\prime}\left(I_{i}^{j *}\right)$, so Eq. (4.14) becomes

$$
\dot{I}_{i}^{j}=-\frac{1}{C_{i}^{\prime \prime}\left(I_{i}^{j *}\right)} \cdot\left[-\left(r+\delta_{i}^{j}\right) \cdot C_{i}^{\prime}\left(I_{i}^{j *}\right)-\frac{\partial C_{i}^{*}(\cdot)}{\partial k_{i}^{j}}+\sum_{s} \lambda_{s} \cdot \frac{\partial f_{s}^{*}(\cdot)}{\partial k_{i}^{j}}\right]=G\left(k_{i}^{j}, I_{i}^{j}\right) \ldots
$$

Due to the nonlinearity of the dynamic system defined by $\dot{k}_{i}^{j}, \dot{I}_{i}^{j}$, the global stability of this system cannot be easily investigated. As this system is autonomous, the following linearised system in the neighbourhood of its steady state is a good 
approximation to the original non-linear system formed by Eq. (4.8) and (4.17) around the steady state equilibrium (Gandolfo 1997).

When $x^{*}$ is an equilibrium, $\dot{x}(t)=A\left(x(t)-x^{*}\right), A=\left[\frac{\partial f_{i}\left(x^{*}\right)}{\partial x_{j}}\right], i, j=1,2, \ldots n . A$ is the Jacobian matrix of the system evaluated at the equilibrium point. If the equilibrium point in the linear approximation is globally stable, then it is locally stable at the original non-linear system. The converse is not necessarily true (Xepapadeas 1997).

For the original non-linear system formed by Eq. (4.8) and (4.17),

$A \equiv\left[\begin{array}{ll}\frac{\partial F(\cdot)}{\partial k_{i}^{j}}, & \frac{\partial F(\cdot)}{\partial I_{i}^{j}} \\ \frac{\partial G(\cdot)}{\partial k_{i}^{j}}, & \frac{\partial G(\cdot)}{\partial I_{i}^{j}}\end{array}\right]_{\left(\begin{array}{ll}k_{i}^{j}=k_{i}^{j *} \\ I_{i}^{j}=I_{i}^{j *}\end{array}\right.}=\left[\begin{array}{ll}a_{11}, & a_{12} \\ a_{21}, & a_{22}\end{array}\right]$, in which

$a_{11}=-\delta_{i}^{j}<0$,

$a_{12}=1$,

$a_{21}=-C_{i}^{\prime \prime}\left(I_{i}^{j *}\right)^{-1} \cdot\left(\sum_{s} \lambda_{s} \cdot \frac{\partial^{2} f_{s}^{*}(\cdot)}{\partial k_{i}^{j^{2}}}-\frac{\partial^{2} C_{i}^{*}(\cdot)}{\partial k_{i}^{j^{2}}}\right)$,

$a_{22}=r+\delta_{i}^{j}>0{ }^{1}$

${ }^{1}$ The value of element $a_{22}$ in the Jacobian matrix determined as below;

$$
\begin{gathered}
a_{22}=\frac{\partial G(\cdot)}{\partial I_{i}^{j}}=-C_{i}^{\prime \prime}\left(I_{i}^{j *}\right)^{-2} \cdot\left\{\left[-\left(r+\delta_{i}^{j}\right) \cdot C_{i}^{\prime \prime}\left(I_{i}^{j *}\right) \cdot C_{i}^{\prime \prime}\left(I_{i}^{j *}\right)-C_{i}^{(3)}\left(I_{i}^{j *}\right) \cdot\right.\right. \\
\left.\left[-\left(r+\delta_{i}^{j}\right) \cdot C_{i}^{\prime}\left(I_{i}^{j *}\right)-\frac{\partial C_{i}^{*}(\cdot)}{\partial k_{i}^{j}}+\sum_{s} \lambda_{s} \cdot \frac{\partial f_{s}^{*}(\cdot)}{\partial k_{i}^{j}}\right]\right\}
\end{gathered}
$$

$C_{i}^{\prime \prime}\left(I_{i}^{j *}\right)$ and $C_{i}^{(3)}\left(I_{i}^{j *}\right)$ denote the second and third order differentiation against the investments in each of the three sectors respectively. Since $\dot{I}_{i}^{j}=0$ when $I_{i}^{j}=I_{i}^{j *}$, from Eq. (4.17)

$$
\begin{aligned}
& -\left(r+\delta_{i}^{j}\right) \cdot C_{i}^{\prime}\left(I_{i}^{j *}\right)-\frac{\partial C_{i}^{*}(\cdot)}{\partial k_{i}^{j}}+\sum_{s} \lambda_{s} \cdot \frac{\partial f_{s}^{*}(\cdot)}{\partial k_{i}^{j}}=0 . \text { Therefore, } \\
& a_{22}=\frac{\partial G(\cdot)}{\partial I_{i}^{j}}=-C_{i}^{\prime \prime}\left(I_{i}^{j *}\right)^{-2} \cdot\left[-\left(r+\delta_{i}^{j}\right) \cdot C_{i}^{\prime \prime}\left(I_{i}^{j *}\right) \cdot C_{i}^{\prime \prime}\left(I_{i}^{j *}\right)\right]=\left(r+\delta_{i}^{j}\right) .
\end{aligned}
$$


If $\operatorname{det} A=a_{11} a_{22}-a_{12} a_{21} \neq 0$, the qualitative behaviour of the trajectories of the non-linear system in the neighbourhood of its steady state point $\left(k_{i}^{j *}, I_{i}^{j *}\right)$ is the same as that of the linearized homogeneous system (Xepapadeas 1997). The sign of $\operatorname{det} A$ then indicates the stability properties of the dynamic system.

The signs of the partial derivatives of costs and water quality with respect to $k_{i}^{j}$ and $I_{i}^{j}$ determine the sign of $\operatorname{det} A$. Since it is more expensive to accelerate the increase in capital stock, $C_{i}^{\prime}\left(I_{i}^{j}\right)>0, C_{i}^{\prime \prime}\left(I_{i}^{j}\right) \geq 0$. From the relationship stated in Eq. (4.9), it is also reasonable to assume $\frac{\partial C_{i}(\cdot)}{\partial k_{i}^{j}}>0, \frac{\partial^{2} C_{i}(\cdot)}{\partial k_{i}^{j^{2}}} \geq 0^{2}$. For the partial derivatives of water quality to the capital stock in each sector, it follows that $\frac{\partial f_{s}(\cdot)}{\partial k_{i}^{q}}<0, \frac{\partial f_{s}(\cdot)}{\partial k_{i}^{\beta}}<0$ and $\frac{\partial f_{s}(\cdot)}{\partial k_{i}^{a}}>0$. Due to the increasing marginal damage of water pollution, I can assume that $\frac{\partial f_{s}^{2}(\cdot)}{\partial k_{i}^{q^{2}}} \leq 0, \frac{\partial f_{s}^{2}(\cdot)}{\partial k_{i}^{\beta^{2}}} \leq 0$. On the other hand, the effect of abatement on pollution effluent is either constant or diminishing in most of the situations, i.e. $\frac{\partial f_{s}^{2}(\cdot)}{\partial k_{i}^{a^{2}}} \leq 0$.

From the discussion and assumptions above, it is not difficult to see that $\operatorname{det} A=a_{11} a_{22}-a_{12} a_{21}<0, \forall j$. Therefore the eigenvalues of the Jacobian matrix $A$ are of opposite sign. The steady state point $\left(k_{i}^{j *}, I_{i}^{j *}\right)$ of the non-linear dynamic system $\dot{I}_{i}^{j}$ is a saddle point equilibrium for the capital stock and investment, and the trajectories in the plane display a property of a saddle point, at least locally.

\subsubsection{Qualitative analysis: phase diagram}

Since many dynamic systems of non-linear differential equations cannot be solved analytically, the qualitative properties of their solutions can sometimes be described and examined by a graphic device, phase diagram (Léonard and Long 1992).

\footnotetext{
${ }^{2}$ This may not always be true in reality. An exceptional case in reality could be found in Hanley et al. (1998), in which the abatement of pollution in a particularly large firm has decreasing marginal cost, i.e. $\frac{\partial^{2} C_{i}(\cdot)}{\partial k_{i}^{a^{2}}}<0$.
} 


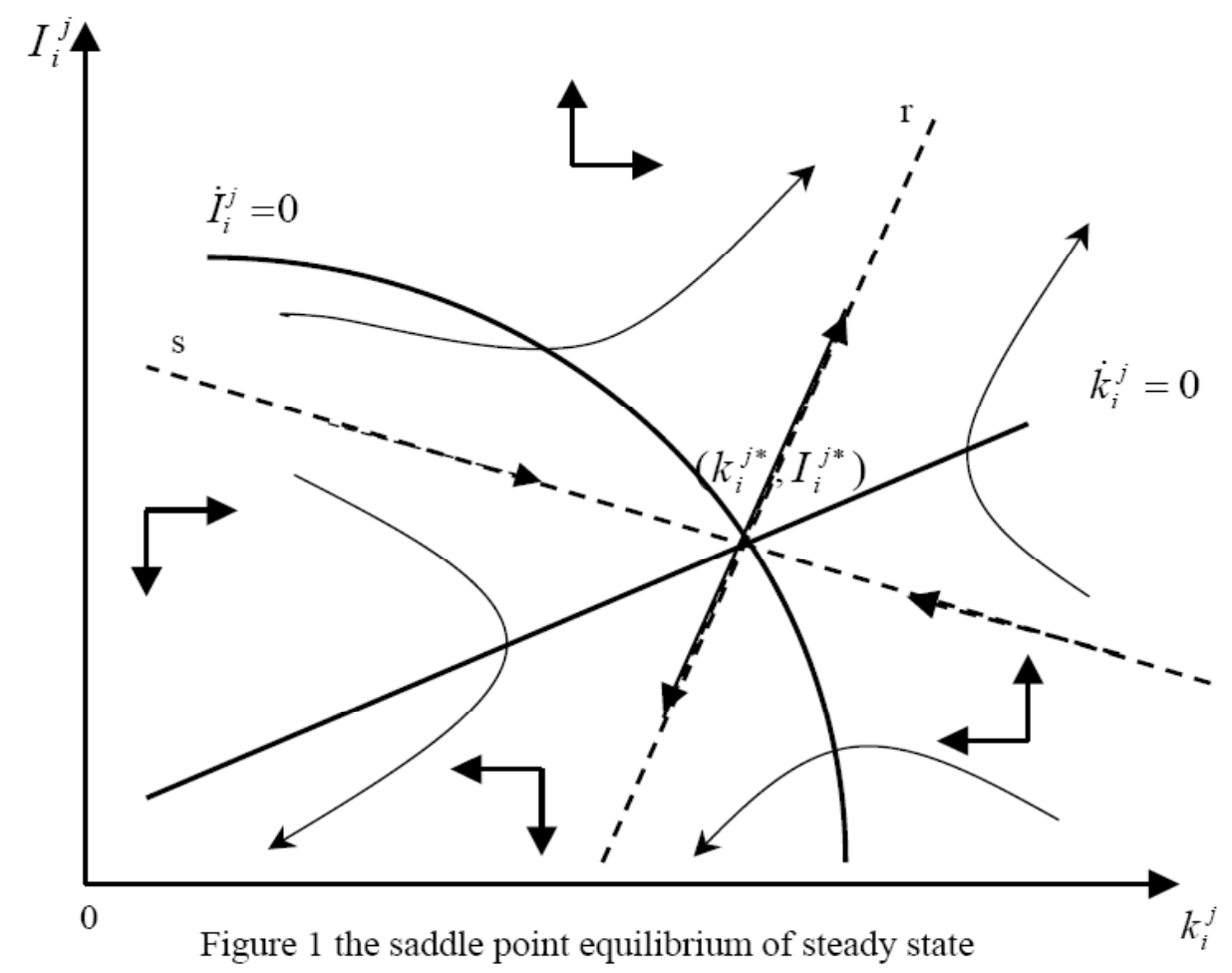

The intersection of the lines $\dot{k}_{i}^{j}=0$ and $\dot{I}_{i}^{j}=0$ is the saddle point steady state equilibrium $\left(k_{i}^{j^{*}}, I_{i}^{j *}\right)$ in the coordinated system of $\left(k_{i}^{j}, I_{i}^{j}\right)$ which is illustrated by the phase plane of the system ${ }^{3}$. When $\frac{\partial^{2} f_{s}^{*}(\cdot)}{\partial k_{i}^{j^{2}}}, \frac{\partial^{2} C_{i}^{*}(\cdot)}{\partial k_{i}^{j^{2}}}$ and $C_{i}^{\prime \prime}\left(I_{i}^{j *}\right)$ are continuous, the function of the slope for $\dot{I}_{i}^{j}=0$ implies that $\lim _{k_{i}^{j} \rightarrow 0}-\left(G_{k} / G_{I}\right)=0$ and $\lim _{k_{i}^{j} \rightarrow 0}-\left(G_{k} / G_{I}\right)-\infty$, where $k_{i \max }^{j}$ is the maximum value $k_{i}^{j}$ could take ${ }^{4}$. The sign of $\dot{k}_{i}^{j}, \dot{I}_{i}^{j}$ in the regions separated by their isoclines are also determined.

${ }^{3}$ The shape of the isoclines are defined as $-\left(F_{k} / F_{I}\right)$ and $-\left(G_{k} / G_{I}\right)$ respectively: $\dot{k}_{i}^{j}=0 \Rightarrow \frac{\partial I_{i}^{j}}{\partial k_{i}^{j}}=-\left(F_{k} / F_{I}\right)=\delta_{i}^{j}>0$

$\dot{I}_{i}^{j}=0 \Rightarrow \frac{\partial I_{i}^{j}}{\partial k_{i}^{j}}=-\left(G_{k} / G_{I}\right)=-\frac{\sum_{s} \lambda_{s} \cdot \frac{\partial^{2} f_{s}^{*}(\cdot)}{\partial k_{i}^{j^{2}}}-\frac{\partial^{2} C_{i}^{*}(\cdot)}{\partial k_{i}^{j^{2}}}}{-C_{i}^{\prime \prime}\left(I_{i}^{j^{*}}\right)^{-1} \cdot\left(r+\delta_{i}^{j}\right)} \leq 0$.

\footnotetext{
${ }^{4}$ Recalling the increasing marginal damage to the water quality from effluent discharge and water abstraction, and the diminishing marginal effects of pollution
} 
$\frac{\partial \dot{I}_{i}^{j}}{\partial I_{i}^{j}}=r+\delta_{i}^{j}>0$. Holding $k_{i}^{j}$ constant, an increase in $I_{i}^{j}$ will result in an increase in $\dot{I}_{i}^{j}, \dot{I}_{i}^{j}$ is positive above $\dot{I}_{i}^{j}=0$ and negative below it. Similarly, $\frac{\partial \dot{k}_{i}^{j}}{\partial k_{i}^{j}}=-\delta_{i}^{j}<0$, so $\dot{k}_{i}^{j}$ is negative to the right of isocline $\dot{k}_{i}^{j}=0$ and positive to the left. The phase diagram is illustrated as Figure 1.

Since we have shown that the Jacobian matrix $A$ has a negative determinant, the dynamic system above is unstable with saddle point equilibrium at $\left(k_{i}^{j *}, I_{i}^{j *}\right)$. A unique property of saddle point equilibrium is that there is only one trajectory in the plan would converge to the steady state equilibrium while others only diverge away from it (Hoy et al. 2001). The two lines, s and r, determined by the eigenvectors of the Jacobian matrix $A$ respectively, are the asymptotes to all the remaining trajectories (Gandolfo 1997), while $\mathrm{s}$ is the stable arm of saddle point The analytical and numerical methods for identify the stable arm of saddle-point equilibrium are discussed by Shone (2002) with specified functions.

\subsection{Implication of river policy}

The section below discussed the policy implication of two types of economic incentive instruments, the ETS scheme and TPP system. The environmental economists have advertised these instruments over the last few decades (Oates and Strassmann 1984; Baumol and Oates 1988; Perman et al. 1996; Hanley et al. 1997; Cowan 1998). But in most of the research, the application of these instruments was restrained to static analysis, only few of them discussed the possible implication under dynamic system (Xepapadeas 1997). This paper did not discuss their implication in a static situation, but the implementation in a dynamic regulating system to improve the water quality in a river system. I also pointed out the differences between those under the static analysis.

\subsubsection{ETS scheme}

Under the ETS scheme, a firm in principle is required to pay (receive) an aggregate emission and water abstraction tax (subsidy) at any site along the river, depends on whether they discharge or abstract more than the baseline right they are initially allowed by the environment authority. The tax (subsidy) for source at site $i$ is $T_{i e}+T_{i a}=\sum_{s}\left(e_{i}-e_{i}^{0}\right) \cdot b_{i s} \cdot t_{e s}+\sum_{s}\left(\beta_{i}-\beta_{i}^{0}\right) \cdot d_{i s} \cdot t_{a s}$, where $t_{e s}$ and $t_{a s}$ are the tax rates for effluent discharge or water abstraction at site $s$ that the firm affects. Thus the objective of a cost-minimizing firm under the ETS is to 
$\operatorname{Min}_{I_{i}^{j}} \int_{0}^{\infty} e^{-r t} \cdot\left[C_{i}\left(q_{i}\left(k_{i}^{q}\right), a_{i}\left(k_{i}^{a}\right), \beta_{i}\left(k_{i}^{\beta}\right), I_{i}^{j}\right)+\sum_{s} t_{e s} b_{i s}\left(e_{i}-e_{i}^{0}\right)+\sum_{s} t_{a s} d_{i s}\left(\beta_{i}-\beta_{i}^{0}\right)\right]$

s.t. Eq. (4.2), $e(t) \geq 0, \beta(t) \geq 0$ and $k_{i}^{j}(0)$ is given.

The current value Hamiltonian for the problem is

$$
\hat{H}=C_{i}\left(q_{i}, a_{i}, \beta_{i}, I_{i}^{j}\right)+\sum_{s} t_{e s} b_{i s}\left(e_{i}-e_{i}^{0}\right)+\sum_{s} t_{a s} d_{i s}\left(\beta_{i}-\beta_{i}^{0}\right)+\sum_{j} \mu_{i}^{j} \cdot\left(I_{i}^{j}-\delta_{i}^{j} \cdot k_{i}^{j}\right)
$$

The following FOCs are then implied:

$I_{i}^{j} \cdot\left(\frac{\partial C_{i}^{*}(\cdot)}{\partial I_{i}^{j}}+\mu_{i}^{j}\right)=0, I_{i}^{j} \geq 0$

$\dot{\mu}_{i}^{j}=\left(r+\delta_{i}^{j}\right) \mu_{i}^{j}-\frac{\partial C_{i}^{*}(\cdot)}{\partial k_{i}^{j}}-\sum_{s}\left(t_{e s} \cdot b_{i s} \cdot \frac{\partial e_{i}^{*}}{\partial k_{i}^{j}}+t_{a s} \cdot d_{i s} \cdot \frac{\partial \beta_{i}^{*}}{\partial k_{i}^{j}}\right)$,

$\dot{k}_{i}^{j}=I_{i}^{j *}-\delta_{i}^{j} k_{i}^{j *}$,

along with the transversality condition (4.10).

The variation of the investment in each sector of capital stock is derived from:

$$
\dot{I}_{i}^{j}=-C_{i}^{\prime \prime}\left(I_{i}^{j}\right)^{-1} \cdot\left[\left(r+\delta_{i}^{j}\right) \mu_{i}^{j}-\frac{\partial C_{i}^{*}(\cdot)}{\partial k_{i}^{j}}-\sum_{s}\left(t_{e s} \cdot b_{i s} \cdot \frac{\partial e_{i}^{*}}{\partial k_{i}^{j}}+t_{a s} \cdot d_{i s} \cdot \frac{\partial \beta_{i}^{*}}{\partial k_{i}^{j}}\right)\right] \ldots
$$

Comparing the FOCs under the ETS and relative to (4.6) to (4.10), when the following tax rates are set for discharge effluent and water abstraction: $t_{e s}=-\lambda_{s} \cdot \frac{\partial f_{s}^{*}(\cdot)}{\partial E_{s}}$ and $t_{a s}=-\lambda_{s} \cdot \frac{\partial f_{s}^{*}(\cdot)}{\partial H_{s}}$, the equilibria achieved through cost minimization management would be the same as the pollution control optimum of minimized cost through direct control.

When these tax rates are applied, not only the two different policy instruments would lead to the same equilibrium, it also insures that the dynamic of the systems under the two policy instruments have the same properties of stability. That is, the dynamic system under ETS has saddle point equilibrium with only one trajectory converging to the steady state equilibrium. Due to the difficulty of evaluating the appropriate value of shadow price $\lambda_{s}$, tax rates might not always lead to the optimum, thus the ETS might not be cost efficient. However, recalling the Jacobian matrix $A$, it can be proved that the 
stability properties of the dynamic system under a ETS will remain the same as long as the tax rates are of the opposite signs of $\frac{\partial f_{s}^{*}(\cdot)}{\partial E_{s}}$ and $\frac{\partial f_{s}^{*}(\cdot)}{\partial H_{s}}$.

\subsubsection{TPP system}

In a TPP system a firm receives an initial quantity of effluent discharge permits or water abstraction licenses or both, either through auction or "grandfathering" distribution from the environment authority, denoted as $e_{i s}^{0}$ and $\beta_{i s}^{0}$ for the site $s$ from the firm at site $i$. The firm will demand more permits if its pollution emission and water abstraction effects exceed the permits they hold for any site, if it is more costly to increase abatement capacity or reduce production or vice versa.

Although TPP and tax schemes are usually regarded as having equivalent effects, there are still some differences between them. One is that the optimal value of the tax rates requires has to be chosen by the environment authority while in the TPP system the price is achieved by market automatically. Another important difference is that pollution permits are rights to pollute. Once they are purchased, pollution is allowed. So purchase of pollution permits is more like a lump-sum payment compared with the annual payment as tax or subsidy. Although the recent pollution permits are less likely to be valid forever, permits are often renewable at a negligible price compared with the purchase payment. Since initial permits could be allocated either through "grandfathering" or auction, the model only considers pollution control costs after initial distribution of permits.

The objective of cost minimization for the firm at site $i$ (assuming its effluent discharge and water abstraction are carried out locally) can be indicated as below:

$$
\operatorname{Min}_{I_{i}^{j}} \int_{0}^{\infty} e^{-r t} \cdot\left[C_{i}\left(q_{i}\left(k_{i}^{q}\right), a_{i}\left(k_{i}^{a}\right), \beta_{i}\left(k_{i}^{\beta}\right), I_{i}^{j}\right)+\sum_{s} \dot{e}_{i s} \cdot P_{e s}+\sum_{s} \dot{\beta}_{i s} \cdot P_{a s}\right.
$$

s.t. (4.2), $e(t) \geq 0, \beta(t) \geq 0$ and $k_{i}^{j}(0)$ is given.

Since

$\dot{e}_{i s}=\frac{\partial e_{i s}}{\partial t}=b_{i s} \cdot \frac{\partial e_{i}}{\partial t}=b_{i s} \cdot \frac{\partial e_{i}}{\partial k_{i}^{j}} \cdot \frac{\partial k_{i}^{j}}{\partial t}=b_{i s} \cdot \frac{\partial e_{i}}{\partial k_{i}^{j}} \cdot \dot{k}_{i}^{j}, j=q, a$,

and similarly $\dot{\beta}_{i s}=d_{i s} \cdot \frac{\partial \beta_{i}}{\partial k_{i}^{j}} \cdot \dot{k}_{i}^{j}$, the (4.20) can be rewritten as:

$\operatorname{Min} \int_{0}^{\infty} e^{-r t} \cdot\left(C_{i}\left(q_{i}, a_{i}, \beta_{i}, I_{i}^{j}\right)+\sum_{s} b_{i s} \cdot \frac{\partial e_{i}}{\partial k_{i}^{j}} \cdot \dot{k}_{i}^{j} \cdot P_{e s}+\sum_{s} d_{i s} \cdot \frac{\partial \beta_{i}}{\partial k_{i}^{j}} \cdot \dot{k}_{i}^{j} \cdot P_{a s}\right) \ldots$ 
The current value Hamiltonian is

$$
\begin{aligned}
\hat{H}=C_{i} & \left(q_{i}, a_{i}, \beta_{i}, I_{i}^{j}\right)+\sum_{s} P_{e s} \cdot b_{i s} \cdot \frac{\partial e_{i}}{\partial k_{i}^{j}} \cdot\left(I_{i}^{j}-\delta_{i}^{j} \cdot k_{i}^{j}\right) \\
& +\sum_{s} P_{a s} \cdot d_{i s} \cdot \frac{\partial \beta_{i}}{\partial k_{i}^{j}} \cdot\left(I_{i}^{j}-\delta_{i}^{j} \cdot k_{i}^{j}\right)+\sum_{j} \mu_{i}^{j} \cdot\left(I_{i}^{j}-\delta_{i}^{j} \cdot k_{i}^{j}\right)
\end{aligned}
$$

The FOCs imply the following equations,

$$
\begin{aligned}
& \frac{\partial \hat{H}}{\partial I_{i}^{j}}=0 \Rightarrow \mu_{i}^{j}=-\left(\frac{\partial C_{i}^{*}(\cdot)}{\partial I_{i}^{j}}+\sum_{s} b_{i s} \cdot \frac{\partial e_{i}^{*}}{\partial k_{i}^{j}} \cdot P_{e s}+\sum_{s} d_{i s} \cdot \frac{\partial \beta_{i}^{*}}{\partial k_{i}^{j}} \cdot P_{a s}\right), \forall j \\
& \dot{\mu}_{i}^{j}=(r\left.+\delta_{i}^{j}\right) \mu_{i}^{j}-\frac{\partial C_{i}^{*}(\cdot)}{\partial k_{i}^{j}}-\sum_{s}\left(P_{e s} \cdot b_{i s} \cdot \frac{\partial^{2} e_{i}^{*}}{\partial k_{i}^{j^{2}}} \cdot \dot{k}_{i}^{j}-P_{e s} \cdot b_{i s} \cdot \delta_{i}^{j} \cdot \frac{\partial e_{i}^{*}}{\partial k_{i}^{j}}\right) \\
& \quad-\sum_{s}\left(P_{a s} \cdot d_{i s} \cdot \frac{\partial^{2} \beta_{i}^{*}}{\partial k_{i}^{j^{2}}} \cdot \dot{k}_{i}^{j}-P_{a s} \cdot d_{i s} \cdot \delta_{i}^{j} \cdot \frac{\partial \beta_{i}^{*}}{\partial k_{i}^{j}}\right), \forall j \\
& \dot{k}_{i}^{j}=I_{i}^{j *}-\delta_{i}^{j} k_{i}^{j *}, \forall j
\end{aligned}
$$

along with the transversality condition (4.10).

In order to examine the steady state and compare it with to the ETS, we differentiate (4.23) with respect to time to obtain:

$$
\dot{\mu}_{i}^{j}=\frac{\partial \mu_{i}^{j}}{\partial t}=\frac{\partial \mu_{i}^{j}}{\partial I_{i}^{j}} \cdot \frac{\partial I_{i}^{j}}{\partial t}=-\frac{\partial C_{i}^{\prime}\left(I_{i}^{j *}\right)}{\partial I_{i}^{j}} \cdot \frac{\partial I_{i}^{j}}{\partial t}=-\partial C_{i}^{\prime \prime}\left(I_{i}^{j *}\right) \cdot \dot{I}_{i}^{j}
$$

Substituting $\mu_{i}^{j}$ and $\dot{\mu}_{i}^{j}$ in Eq. (4.23) and (4.25) into Eq. (4.24) to give:

$$
\begin{aligned}
\dot{I}_{i}^{j}=- & C^{\prime \prime}\left(I_{i}^{j *}\right)^{-1} \cdot\left[-\left(r+\delta_{i}^{j}\right) \cdot \frac{\partial C_{i}^{*}(\cdot)}{\partial I_{i}^{j}}-\frac{\partial C_{i}^{*}(\cdot)}{\partial k_{i}^{j}}-\sum_{s} P_{e s} \cdot b_{i s} \cdot \frac{\partial^{2} e_{i}^{*}}{\partial k_{i}^{j^{2}}} \cdot \dot{k}_{i}^{j}\right. \\
& -\sum_{s} P_{a s} \cdot d_{i s} \cdot \frac{\partial^{2} \beta_{i}^{*}}{\partial k_{i}^{j^{2}}} \cdot \dot{k}_{i}^{j}-\sum_{s} r \cdot P_{e s} \cdot b_{i s} \cdot \frac{\partial e_{i}^{*}}{\partial k_{i}^{j}}-\sum_{s} r \cdot P_{a s} \cdot d_{i s} \cdot \frac{\partial \beta_{i}^{*}}{\partial k_{i}^{j}}
\end{aligned}
$$

In the steady state where $\dot{k}_{i}^{j}=\dot{I}_{i}^{j}=\dot{\mu}_{i}^{j}=0,(4.26)$ is equivalent to (4.19) when $P_{e s}=t_{e s} / r$ and $P_{a s}=t_{a s} / r$, which is derived under the ETS. Therefore the ETS and TPP system lead to the same steady state equilibrium for investment and capital stock in each sector. This result implies that purchase of one pollution permit the firm saves the firm an infinite stream of tax payment for this unit of pollution. Therefore it needs to pay an amount equal to the present value of the aggregate tax payment. The convergence and stability properties of the steady state equilibrium in the TPP system are the same as that in the ETS. 


\subsection{Comparative Statics}

\subsubsection{Short-run ${ }^{5}$ comparative statics}

Assuming the effluent discharge is a function of the output and abatement, $e_{i}=Z_{i}\left(q_{i}, \alpha_{i}\right)$, the short-run maximum principle of static analysis in the ETS can be obtained as

$$
\begin{aligned}
& \frac{\partial \hat{H}}{\partial e_{i}}=\frac{\partial C_{i}^{*}(\cdot)}{\partial e_{i}}+\sum_{s} t_{e s} \cdot b_{i s}=0 \\
& \frac{\partial \hat{H}}{\partial \beta_{i}}=\frac{\partial C_{i}^{*}(\cdot)}{\partial \beta_{i}}+\sum_{s} t_{a s} \cdot d_{i s}=0
\end{aligned}
$$

Due to the implicit function theorem (Gandolfo 1997; Xepapadeas 1997; Hoy et al. 2001), the short-run comparative statics based on the (4.27) and (4.28) gives the effects of the changes in effluent tax rate on the effluent discharge and water abstraction:

$$
\left[\begin{array}{cc}
C_{e e}, & C_{e \beta} \\
C_{e \beta}, & C_{\beta \beta}
\end{array}\right] \cdot\left[\begin{array}{l}
\partial e_{i} / \partial t_{e s} \\
\partial \beta_{i} / \partial t_{e s}
\end{array}\right]=\left[\begin{array}{c}
-b_{i s} \\
0
\end{array}\right]
$$

where $C_{e e}$ represents the second order partial derivative of cost function with respect to effluent discharge. The abatement costs are assumed to have increasing marginal costs, i.e. $C_{e e}, C_{e \beta}, C_{\beta \beta} \geq 0$.

When $|D|=C_{e e} \cdot C_{\beta \beta}-C_{e \beta}^{2}>0$, applying the Cramer's rule, it can be shown that

$$
\frac{\partial e_{i}}{\partial t_{e s}}=\frac{\left[\begin{array}{cc}
-b_{i s}, & C_{e \beta} \\
0 & C_{\beta \beta}
\end{array}\right]}{|D|} \leq 0 \text { and } \frac{\partial \beta_{i}}{\partial t_{e s}}=\frac{\left[\begin{array}{cc}
C_{e e} & -b_{i s}, \\
C_{e \beta} & 0
\end{array}\right]}{|D|} \geq 0 .
$$

Similarly, there is $\left[\begin{array}{ll}C_{e e}, & C_{e \beta} \\ C_{e \beta}, & C_{\beta \beta}\end{array}\right] \cdot\left[\begin{array}{l}\partial e_{i} / \partial t_{a s} \\ \partial \beta_{i} / \partial t_{a s}\end{array}\right]=\left[\begin{array}{c}0 \\ -d_{i s}\end{array}\right]$

so $\frac{\partial e_{i}}{\partial t_{a s}}=\frac{\left[\begin{array}{cc}-b_{i s}, & C_{e \beta} \\ 0 & C_{\beta \beta}\end{array}\right]}{|D|} \leq 0$ and $\frac{\partial \beta_{i}}{\partial t_{a s}}=\frac{\left[\begin{array}{cc}C_{e e} & -b_{i s}, \\ C_{e \beta} & 0\end{array}\right]}{|D|} \geq 0$.

Therefore, it can be shown analytically that when the tax rate on one pollution type (either effluent discharge or water abstraction) increases, the corresponding activity will be restrained due to the more potent policy while other activities will become relatively "cheaper" to apply.

\footnotetext{
${ }^{5}$ Short-run here refer to the period during which the plant is unable to vary its capacity of effluent and abstraction through capital investment, but abatement can vary within the current capacity.
} 


\subsubsection{Steady state comparative statics}

At the steady state, $\dot{I}_{i}^{j}=\dot{k}_{i}^{j}=0$, implying that

$$
\begin{aligned}
& -C_{i}^{\prime \prime}\left(I_{i}^{j *}\right)^{-1} \cdot\left[\left(r+\delta_{i}^{j}\right) \mu_{i}^{j}-\frac{\partial C_{i}^{*}(\cdot)}{\partial k_{i}^{j}}-\sum_{s}\left(t_{e s} \cdot b_{i s} \cdot \frac{\partial e_{i}^{*}}{\partial k_{i}^{j}}+t_{a s} \cdot d_{i s} \cdot \frac{\partial \beta_{i}^{*}}{\partial k_{i}^{j}}\right)\right]=0 \ldots \\
& G\left(k_{i}^{j *}, I_{i}^{j *}\right)=I_{i}^{j *}-\delta_{i}^{j} k_{i}^{j *}=0
\end{aligned}
$$

Because $C_{i}^{\prime \prime}\left(I_{i}^{j *}\right)^{-1} \neq 0$ and (4.11), this can be reduced to

$$
F\left(k_{i}^{j *}, I_{i}^{j *}\right)=-\left(r+\delta_{i}^{j}\right) \cdot \frac{\partial C_{i}^{*}(\cdot)}{\partial I_{i}^{j}}-\frac{\partial C_{i}^{*}(\cdot)}{\partial k_{i}^{j}}-\sum_{s}\left(t_{e s} \cdot b_{i s} \cdot \frac{\partial e_{i}^{*}}{\partial k_{i}^{j}}+t_{a s} \cdot d_{i s} \cdot \frac{\partial \beta_{i}^{*}}{\partial k_{i}^{j}}\right)=0
$$

when $\frac{\partial e_{i}^{*}}{\partial k_{i}^{\beta}}=0$ and $\frac{\partial \beta_{i}^{*}}{\partial k_{i}^{q}}=\frac{\partial \beta_{i}^{*}}{\partial k_{i}^{a}}=0$.

Applying the implicit function theorem to (4.33) and (4.32) gives

$$
\left[\begin{array}{cc}
F_{k}, & F_{I} \\
G_{k}, & G_{I}
\end{array}\right] \cdot\left[\begin{array}{l}
\partial k_{i}^{j} / \partial t_{e s} \\
\partial I_{i}^{j} / \partial t_{e s}
\end{array}\right]=\left[\begin{array}{c}
b_{i s} \cdot \frac{\partial e_{i}^{*}}{\partial k_{i}^{j}} \\
0
\end{array}\right]
$$

When $|D|=\left|\begin{array}{ll}F_{k}, & F_{I} \\ G_{k}, & G_{I}\end{array}\right| \neq 0$, it obtains that $\frac{\partial k_{i}^{j}}{\partial t_{e s}}=\frac{b_{i s} \cdot \frac{\partial e_{i}^{*}}{\partial k_{i}^{j}}}{|D|}$ and $\frac{\partial I_{i}^{j}}{\partial t_{e s}}=\frac{\delta_{i}^{j} \cdot b_{i s} \cdot \frac{\partial e_{i}^{*}}{\partial k_{i}^{j}}}{|D|}$. Since $|D|=F_{k} \cdot G_{I}-F_{I} \cdot G_{k}<0^{6}, \frac{\partial k_{i}^{j}}{\partial t_{e s}}$ and $\frac{\partial I_{i}^{j}}{\partial t_{e s}}$ will always have opposite sign of $\frac{\partial e_{i}^{*}}{\partial k_{i}^{j}}$, and $\frac{\partial I_{i}^{j}}{\partial t_{e s}}=\delta_{i}^{j} \cdot \frac{\partial k_{i}^{j}}{\partial t_{e s}}$. Similarly, we have that $\frac{\partial k_{i}^{j}}{\partial t_{a s}}=\frac{d_{i s} \cdot \frac{\partial \beta_{i}^{*}}{\partial k_{i}^{j}}}{|D|}$ and $\frac{\partial I_{i}^{j}}{\partial t_{a s}}=\frac{\delta_{i}^{j} \cdot d_{i s} \cdot \frac{\partial \beta_{i}^{*}}{\partial k_{i}^{j}}}{|D|}$.

The comparative statics in the steady state indicate different effects compared with the short run effects. An increase in tax rates on one particular pollution activity reduces the activity, as it does in the short run. But in the steady state the capital stock and investment level in other activities are independent of the change. This is due to the independence of investment sectors.

${ }^{6}$ It can be proved that $F_{k} \leq 0, F_{I} \leq 0, G_{k}=-\delta_{i}^{j}<0, G_{I}=1$ since $\frac{\partial^{2} C_{i}(\cdot)}{\partial k_{i}^{j *} \cdot \partial I_{i}^{j *}} \geq 0$ 
The results of comparative statics on the TPP system are very similar to those for a ETS (Xepapadeas 1997). Therefore the comparative statics under both instruments are summarized in Table 1 and 2.

Table 1: Short-run comparative statics

\begin{tabular}{|c|c|c|}
\hline & $e_{i}$ & $\beta_{i}$ \\
\hline$t_{e s}$ & - & + \\
\hline$t_{a s}$ & + & - \\
\hline$P_{e s}$ & - & + \\
\hline$P_{a s}$ & + & - \\
\hline
\end{tabular}

Table 2: Steady State Comparative Statics

\begin{tabular}{|c|c|c|c|c|c|c|}
\hline & $k_{i}^{q}$ & $k_{i}^{a}$ & $k_{i}^{\beta}$ & $I_{i}^{q}$ & $I_{i}^{a}$ & $I_{i}^{\beta}$ \\
\hline$t_{e s}$ & - & + & 0 & - & + & 0 \\
\hline$t_{a s}$ & 0 & 0 & - & 0 & 0 & - \\
\hline$P_{e s}$ & - & + & 0 & - & + & 0 \\
\hline$P_{a s}$ & 0 & 0 & - & 0 & 0 & - \\
\hline
\end{tabular}

\section{Empirical example of water quality management in tidal}

\section{$\underline{\text { Ouse }}$}

This empirical example described the methods and result of static optimisation when the variation of assimilative capacity was taken into account by including various options to improve the water quality in tidal Ouse. In this optimisation, the variation of assimilative capacity was assorted with the effects of changing the location of effluent discharge. For the first time, the option of reducing water abstraction to improvement assimilative capacity and water quality was also integrated with the standard option of reducing effluent discharge. Therefore, reducing effluent discharge, changing discharge location and reducing water abstraction were integrated evaluated against their effects on improving water quality and corresponding cost incurred, to achieve the least cost of obtaining the required water quality in the tidal Ouse.

QUESTS1D model, which is a hydrological model used by the EA to set the effluent consents in the tidal Ouse was utilized in this research to predict the resulted water quality at different WQM sites under various conditions. The simulation results of QUESTS1D model were used to generate a system of water quality functions that can predict the water qualities just based on a few most influencing factors. QUEST1D divided the tidal Ouse into 282 cells, around $1 \mathrm{~km}$ each. The system of water quality 
functions consisted of five functions for five different cells in the QUESTS1D model around three WQM sites, which are likely experience severe DO sag issue during low flow summer. In this research, they were the water qualities of cell 180 at Selby, cell 192 and 193 at Long Drax, and cell 197 and 199 at Boothferry Bridge, in terms of 5\%ile DO\%. The most influencing factors to the water qualities of these cells include the effluent discharge levels from both industries and Sewage Treatment Plants (STWs), water abstraction from river Ouse and Derwent, and the effluent discharge location. The associated cots of these options were estimated based on the data provided by the industries and EA. The summation of annual costs was to be minimised against given water quality target in the tidal Ouse.

The static optimisation was calculated through the General Algebraic Modelling System (GAMS) to provide the optimal solution for the cost minimisation. It was proved that relocating the effluent discharges was most effective measure to improve the water quality. With effluents from Selby area being discharged at downstream of the river Ouse, the water quality along the river Ouse could be significantly improved even in the low flow conditions as 1996, but at less cost than it incur currently.

\subsection{Constraints: the System of Water Quality Functions}

The simplified system of water quality function for the following points in 1996 is shown as below Table 3. The first column is the number of cells predicted through the simplified system. The numbers of the cells to be predicted through the system of water quality functions are chosen at 180,192, 193, 197 and 199. Cell 180 is around WQM site at Selby, while cell 192 and 193 locate at Long Drax and cell 197 and 199 at Boothferry Bridge. The WQM sites of Naburn Weir and Cawood are not regarded to be at risk as their DO\% are more than $60 \%$ even in the worst situation in 1996, therefore the water quality functions did not take into account these two sites. The same reason applies to Blacktoft, where the water quality is basically dominated by the flow of Trent and is consistent over various management options in river Ouse. The water qualities at the five points are predicted simultaneously through this system of functions as $5 \%$ ile DO $\%$ of the cell.

Table 3: Coefficients table of the system of water quality functions

\begin{tabular}{|c|c|c|c|c|c|c|c|c|c|}
\hline Cell & constant & $X$ & $X^{2}$ & $\operatorname{In}($ SBOD) & $\operatorname{In}$ (Ouse) & $\operatorname{In}($ Derw) & $\operatorname{In}($ Sna) & $\operatorname{In}$ (Sand) & $\operatorname{In}($ Tho) \\
\hline 180 & -442.09 & 1.474 & -0.042 & -3.604 & 128.210 & 9.220 & None & None & None \\
\hline 192 & -113.406 & -0.028 & -0.020 & -9.238 & 37.174 & 23.418 & None & None & None \\
\hline 193 & -79.943 & -0.424 & -0.011 & -9.432 & 28.993 & 23.206 & None & None & None \\
\hline 197 & 37.749 & -1.552 & 0.019 & -9.032 & 1.060 & 17.697 & 0.141 & -0.228 & 0.085 \\
\hline 199 & 42.566 & -1.518 & 0.020 & -8.922 & -0.763 & 16.800 & 0.160 & -0.261 & 0.098 \\
\hline
\end{tabular}


The sequent nine variables are the estimators of water quality function: the first one is constant; the $X$ in the second and third column is the distance from discharge location to the Trent Fall in kilometre. SBOD is the total tonnes of BOD5 discharged from the sources around Selby per day, from three industries in Selby and the Barlby and Selby STWs. Ouse and Derwent are river flows (m3/s) of rivers Ouse and Derwent while the flows of other tributaries remains unchanged. Sna, Sand and Tho are another three different STWs in the tributaries Aire and Don, having no effects on the first three points. The location of effluent discharges is best fit to the water quality as a quadratic function, as the improvement is quite slow when $X$ is large (very upstream) or small (very downstream), but faster in the mid-range of tidal Ouse. The effect of $\mathrm{BOD}_{5}$ discharge on water quality is best described as logarithmic function, so is the effect of river flow. This is understandable as both of the factors have diminishing marginal effect on the water quality. See Appendix 1 for the details of the regression analysis.

\subsection{Objectives: Cost Functions of Pollution Abatement}

The objective cost function is the aggregated costs of various options, including the cost of effluent abatement within individual industry and STW, the cost of reducing water abstraction from rivers Ouse and Derwent and the cost of moving the effluent discharges along the river Ouse. The optimal solution is the combination of the three options when their aggregated cost is least and the water quality target is satisfied. All the cost functions were estimated by the cost data provide by the industries and STWs themselves over several years. They were derived from the regression results of statistic package of SPSS and generated highly agreement against the observations. The exact functions were not provided here for confidential reasons.

\subsection{Static Optimisation Analysis}

Having estimated the cost functions of effluent treatment, abstraction reduction, discharge relocation, and the system of water quality functions, an arbitrary water quality target at the water WQM sites to be achieved through the river management options is expected to be obtained at the least costs through the static optimisation. The static optimisation takes the form as below, where $Q_{s}$ and $\bar{Q}_{s}$ are the water quality prediction and target at cell $s$ in terms of DO\%:

$$
\begin{aligned}
& \text { Minimize } C_{\text {total }}=\text { Cost }_{\text {ind }}+\text { Cost }_{\text {STW }}+\text { Cost }_{a b s}+\text { Cost }_{m o v} \\
& \text { s.t. } Q_{s}=f_{s}(X, \text { SBOD, Ouse, Derw, Sna, Sand, Tho }) \geq \bar{Q}_{s}
\end{aligned}
$$


The cells $s$ predicted in this research are cells 180, 192, 193, 197 and 199, reflecting the water qualities at Selby, Long Drax and Boothferry Bridge that are at risk of DO sag during the summer. The arbitrary water quality target for these cells can be various, but is assumed as $30 \% \mathrm{DO} \%$ at $5 \%$ ile in order to protect the return of salmon. All the three options have effects on water quality improvements at different prices. Analysing the effects on water quality and economic cost of the trade-off among these options, the static optimisation is able to find the best combination levels of them, to satisfy the quality target at least cost. When no constraints applied, the optimal solution would be at the point where each option has the same marginal cost over water quality improvement.

This research used General Algebraic Modelling System (GAMS) to find the optimal solution. GAMS has been widely applied for issues involving computable general equilibrium models, particularly become popular in the area of environmental economics to model the cost of environmental policy (Dellink 2005). In this research, GMAS was used to optimise the cost minimization problem facing a given water quality target, through a range of non-linear programming solvers (Brooke et al. 1998; McCarl 2004).

\subsection{Static Optimisation Results}

Due to the European Directive of Urban Waste Water Treatment (UWWTD), it is unlikely in reality to change the abatement levels in the STWs. By far, two of the industries have been using their effluent treatment plants for a quite long period and would have to install new plant if the effluent discharge consents become more stringent. Therefore an optimal solution with slacker abatement requirement would be welcomed by the industries facing international competitions, as well as the local economy of Selby. In this research, all the five STWs (Barlby, Selby, Sna, San and Tho) were assumed to be working at the current levels in 2004 to comply with the UWWTD requirement, while the abatement levels in industries, water abstraction levels and effluent discharge location were all subject to optimisation.

The optimal solution calculated using GAMS was given as below. The abatement in the STWs was fixed at current levels of 2004. The resulted water total abstraction remains unchanged although more water abstraction was advised to be from river Derwent. The optimal abatement levels of the three industries in Selby, water abstraction levels and effluent discharge location were given in Table 4 .

Table 4: Static Optimal Solutions

\begin{tabular}{|c|c|c|c|c|c|c|c|c|c|c|}
\hline $\begin{array}{c}\text { Industry } \\
\text { A }\end{array}$ & $\begin{array}{c}\text { Industry } \\
\text { B }\end{array}$ & $\begin{array}{c}\text { Industry } \\
\text { C }\end{array}$ & $\begin{array}{c}\text { STW } \\
\text { A }\end{array}$ & $\begin{array}{c}\text { STW } \\
\text { B }\end{array}$ & Ouse & Derwent & X & $\begin{array}{c}\text { STW } \\
\text { C }\end{array}$ & $\begin{array}{c}\text { STW } \\
\text { D }\end{array}$ & $\begin{array}{c}\text { STW } \\
\text { E }\end{array}$ \\
\hline 1.081 & 1.081 & 1.081 & 0.599 & 1.955 & 0.637 & 3.530 & 14.890 & 0.498 & 7.902 & 2.954 \\
\hline
\end{tabular}


Table 5: Resulted water qualities at WQM sites

\begin{tabular}{|c|c|c|c|c|c|}
\hline Site & Selby & \multicolumn{2}{|c|}{ Long Drax } & \multicolumn{2}{c|}{ Boothferry Bridge } \\
\hline Cell & $\mathrm{Q}_{180}$ & $\mathrm{Q}_{192}$ & $\mathrm{Q}_{193}$ & Cell & $\mathrm{Q}_{180}$ \\
\hline DO\% & 30.000 & 34.231 & 33.968 & DO $\%$ & 30.000 \\
\hline
\end{tabular}

Table 6: Cost of river management

\begin{tabular}{|c|c|c|c|c|}
\hline & Abatement & Abstraction & Relocation & Total \\
\hline Cost $(\mathrm{m} £)$ & 4.074 & 5.541 & 0.746 & 10.361 \\
\hline
\end{tabular}

In this optimal solution for the least cost of river management, there was no need for the industries in Selby to abate their effluents since the STWs had reduced the pollution more than enough. Reducing water abstraction levels was still too costly as a means of improving water quality than the others. However, since the cost of water abstraction were same, the shifting of water abstraction from Ouse to Derwent suggested that the marginal effect of water abstraction on the water quality was higher in river Ouse than in river Derwent. Therefore it was better to just abstract from river Derwent if possible. The optimal discharge location was $14.890 \mathrm{~km}$ upstream from the Trent Fall, downstream of the confluence of river Don. The dilution effects from tributaries Aire and Don seemed quite promising according to the choice.

Table 5 showed the resulted water qualities at the five points concerned. The two binding points were, $\mathrm{Q}_{180}$ and $\mathrm{Q}_{199}$. The water qualities of the other three points were significantly higher than the requirement. Water quality along the river Ouse was largely improved between Selby and Boothferry compared the current situation, and the DO sag disappeared in the river Ouse even in the year as bad as 1996. The QUESTS1D simulation using the optimal solution confirmed the prediction from the water quality functions. Figure 2 indicated the 5\% ile DO\% along the river Ouse under the optimal solution generated using GAMS.

From the simulation results of QUESTS1D, it can be seen that the predictions from the water quality functions system were generally more pessimistic than the simulation results. This means the optimal solution obtained from GAMS optimisation would result in slightly better water quality in reality, which reduces the risk of failure in compliance due to inevitable model errors and uncertainties. The DO\% of river Ouse following the optimal solution, as indicated in the simulation, decreased first due to the tidal inflow and the resuspended sediments, then slowly increased after Selby and reach the best around Drax, then decrease again, but finally became stable around 35\% and recovered after the confluence with river Trent. 


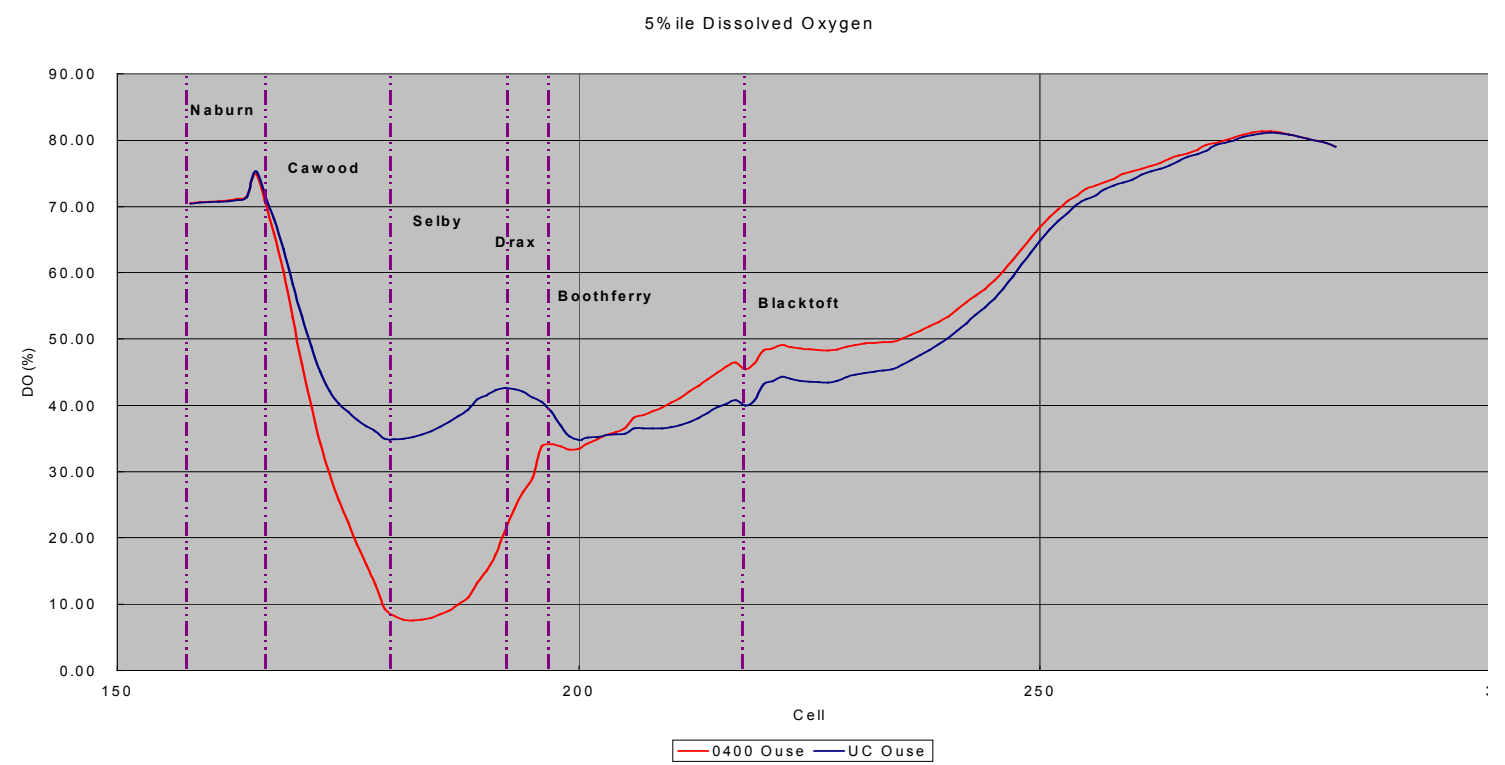

Figure 2: $\mathrm{DO} \%$ under optimal solution

The optimal solution estimated an aggregate cost of at least $£ 10.361 \mathrm{~m}$ for the river management to comply with the $30 \%$ DO\% requirement. However, since the water abstraction was not reduced, the abstraction cost is just to satisfy the water demand rather than improving the water quality. This should not be regarded as the costs incurred by water quality improvement. The rest costs of the effluent abatement and relocating the discharge site account for $£ 4.820 \mathrm{~m}$ in together, achieving much better water quality along the river Ouse at slightly less cost than that is currently endured by the industries and STWs. More than $60 \%$ of the costs of effluent abatement and relocation were contributed from the STWs since their abatement levels remained unchanged. The relocation of effluent discharge only accounted for $15 \%$ of the costs but had obviously much significant impact on the river water quality.

As a virtue of the simplified system of water quality functions, the optimisation could be easily revised against different water quality targets. This makes it very convenient to investigate the difference among solutions to various policy scenarios. Therefore this optimisation system could work for not only the $30 \% \mathrm{DO} \%$ at the selected cells, but also applicable to other water quality targets that are required by the environmental authority.

There are also some potential constraints to the optimal solution. The first one lies into the construction needed to transfer the effluents to new discharge location. Although the annual cost of transfer is just a small proportion of the aggregate annual cost, the capital investment required to build the storage facility and lay down the pipes are almost $£ 10 \mathrm{~m}$. This enormous cost could be a possible obstacle to the acceptance of the solution, especially considering that the STWs would not benefit from the solution since 
they have to maintain the levels of abatement. If the industries were asked to bear capital cost alone, the investment cost would be too high to be accepted by the slim-profited manufacture industries. The second is due to same fact mentioned above. Since the STWs have to maintain their abatement levels because of UWWTD, they would be reluctant to pay for the effluent relocation that make no change to their responsibility of abatement. Reallocation of the benefits among the industries and STWs through negotiation could probably reach a solution for the two constraints in order to ensure the STWs' participation, since the resulted slackness in the industries on effluent discharges were partly attributed by the abatements in the STWs. Appropriate payment to the STWs would motivate their participations while still leave the industries better off, given the payment is not greater than the industries' benefit obtained from the relocation of effluent discharge. This could be achieved through either emission ETS or TPP system. But this is beyond the discussion of this paper. Finally, it is needed to point out that although the STWs could not reduce their abatement levels through the optimal solution, they still benefit from the increased potential of scaling up as the DO sag issue is removed from Selby area by the optimal solution. This is consistent to the increasing demand of sewage services initiated by the increase of population and economy in the North Yorkshire and Lincolnshire (Jarvie et al. 1997) and can reduce the risks of failure in providing sewage service during the extreme conditions such as flood.

\section{$\underline{\text { 6. Conclusion }}$}

The river water quality control in the estuarine system such as Ouse/Humber system is not at all a simple issue. The resuspended sediment due to the tidal movement deteriorates the impacts on the river water quality of effluent discharges from both industry and STWs. This is also accompanied by the impacts of water reduction when significant water volume is taken for supplying water within the whole catchment. Because of the various drivers for the water quality issue in the tidal Ouse, it is not reasonable to regulate on just one of them to improve the water quality. This paper tried to explore an integrated river policy to improve the water quality in the tidal Ouse and remove the DO sag during the summer in order to resume the salmon return. The integrated river policy included the options of improving water quality through reducing effluent discharges from industries and STWs, reducing the water abstraction from various sites and relocating the position of effluent discharges. Optimal solution was provided by solving the constrained optimisation problem of minimizing the cost of river quality management for particular water quality target. 
This paper discussed the necessary conditions for the cost minimisation problem with specific water quality requirement, both under static and dynamic system. In the optimisation issue, the spatial location of effluent discharge and water abstraction were taken into account based on their effects on the water qualities at the EA's WQM site. Reduction in both effluent discharge and water abstraction were also included, and evaluated based on their costs and impacts on water quality improvement. This paper also discussed the mechanism of allocating the pollution abatement and water abstraction among the sources through the policy instruments of ETS scheme and TPP system. The choice of policy instruments in pollution control has been discussed for some time. Most economists agreed that, although there are still limitations in implementation, MBIs have several key advantages over the direct controls, particularly in the cost savings and the continuous motivation to pollution control. This paper showed how the ETS scheme and TPP system could be implemented for water quality management, when the location of emissions and abstraction were taken into account. Some conclusions of the research are as followed:

1. Because of the different location effects of pollution, the equilibrium of least cost solution will take into account both effluents and water abstractions, following the variation of assimilative capacity of the river water.

2. In the static analysis, the least cost equilibrium requires that the ratio between the marginal costs of water abstraction and its effects on the water quality be equal to the marginal costs of effluent discharge and its effects on the water quality, which is the shadow cost of river water quality at the equilibrium.

3. When the dynamic optimisation is considered, in addition to the conditions required in the static analysis, the least cost solution requires that the internal rate of return on investment should equal the rate of return on investment elsewhere in the economy.

4. The steady state equilibrium is a saddle point, therefore the combination of capital stocks and investment decisions has to follow a particular trajectory through which the least cost solutions at each period of time will eventually lead to stable equilibrium of the dynamic system. Since initial capital stocks are determined by exogenous investment choice, there is necessity for the plant to find this temporal investment path in order to achieve the stable equilibrium of the dynamic system.

5. The empirical example of the water quality improvement in the tidal Ouse consists of a system of water quality function derived from QUESTS1D model, and the cost functions of water quality improvement. Solving the constrained optimisation 
problem using GAMS revealed that the, through specific combination of effluent discharge and water abstraction, and location of discharge, the water quality of tidal Ouse could be significantly improved even under the worst flow condition over the last ten years, with less costs than that borne by the industries and STWs. The required water quality target of $30 \% \mathrm{DO} \%$ at $5 \%$ ile what was proved infeasible through the reduction of effluent discharges alone under the flow condition of 1996, can only be achieved through the combining options taking into account effluent relocation and water abstraction reduction.

A relatively novel feature of this research is the integrated management of effluent discharge and water abstraction within the same river policy. The variation of effluent discharge location was considered to reflect the spatial difference between the pollution sources. The integration of this regarding to river policy determination could include the integration of both effluent discharge and water abstraction, integration of timing and spatial effects, and the integration of both physical effect on water quality and economic costs to the society. This research has evaluated these integrations although the variation of timing of effluent discharges was not discussed in this paper due to its impracticability. This integration enables the policy maker to offer sufficient flexibility in the pollution control options available in order to achieve cost effectiveness in the water quality management for the estuarine system, which is consistent to the requirement of WFD. But there are more options and policy instruments that are not considered in this research, and many of them may well be effective even they were not recommended in this research for tidal Ouse. The determination of integrated river policy aiming at achieving the water quality target at the least cost depends on the particular river system and catchment concerned, in order to avoid the disproportionate cost coming from ineffective regulations.

\section{$\underline{\text { References }}$}

Aronsson, T., K.-G. Löfgren and K. Backlund (2004). Welfare Measurement in Imperfect Markets: A Growth Theoretical Approach. Cheltenham, Edward Elgar.

Baumol, W. J. and W. E. Oates (1988). The Theory of Environmental Policy. Cambridge [Cambridgeshire]; New York, Cambridge University Press.

Brooke, A., D. Kendrick, A. Meeraus, R. Raman and R. E. Rosenthal (1998). GAMS: A USER'S GUIDE, GAMS Development Corporation.

Cashman, A., T. Hardy, G. Jones and C. Perrings (1999). Dissolved Oxygen in the Ouse: Cost Effective Solutions, Environment Department, University of York; Environment Agency.

Cowan, S. (1998). "Water pollution and abstraction and economic instruments." Oxford Review of Economic Policy 14(4): 40-49. 
Dellink, R. D. (2005). Modelling the Costs of Environmental Policy: a Dynamic Applied General Equilibrium Assessment, Edward Elgar Publishing, Cheltenham / Northampton.

Edwards, A. M. C., R. J. Freestone and C. P. Crockett (1997). "River management in the Humber catchment." Science of The Total Environment 194-195: 235.

Gandolfo, G. (1997). Economic dynamics. Berlin; London, Springer.

Hanley, N., R. Faichney, A. Munro and J. S. Shortle (1998). "Economic and environmental modelling for pollution control in an estuary." Journal of Environmental Management 52(3): 211.

Hanley, N. and I. Moffatt (1993). "Efficiency and Distributional Aspects of Market Mechanisms in the Control of Pollution: An Empirical Analysis." Scottish Journal of Political Economy 40: 69-87.

Hanley, N., J. F. Shogren and B. White (1997). Environmental Economics in Theory and Practise. Basingstoke, Macmillan.

Hoy, M., J. Livernois, C. Mckenna, R. Ray and T. Stengos (2001). Mathematics for economics, 2nd edition. London, MIT Press.

Jarvie, H. P., C. Neal and A. J. Robson (1997). "The geography of the Humber catchment." Science of The Total Environment 194-195: 87-99.

Law, M., P. Wass and D. Grimshaw (1997). "The hydrology of the Humber catchment." Science of The Total Environment 194-195: 119.

Léonard, D. and N. V. Long (1992). Optimal control theory and static optimisation in economics. Cambridge, Cambridge University Press.

McCarl, B. A. (2004). GAMS User Guide, GAMS Development Corporation.

Oates, W. E. and D. L. Strassmann (1984). "Effluent fees and market structure." Journal of Public Economics 24(1): 29.

Perman, R., Y. Ma, J. McGilvray and M. Common (1996). Natural Resource and Environmental Economics. London and New York, Addison Wesley Longmans.

Rowley, C. e. a. (1979). A Study of Effluent Charges to the Tees. D. o. t. Environment.

Shone, R. (2002). Economic Dynamics: Phase Diagrams and their Economic Application, 2nd Edition. Cambridge, Cambridge University Press.

Turner, R. K., D. Pearce and I. Bateman (1994). Environmental Economics: An Elementary Introduction. New York etc, Harvester Wheatsheaf.

Xepapadeas, A. (1997). Advanced Principles in Environmental Policy. Chelteham and Northampton, Edward Elgar.

Zylicz, T. (2003). "Instruments for water management at the drainage basin scale." Ecological Economics 47(1): 43. 